\title{
A Review of the GPS Tracker GT06N as the Vehicle Tracking Device
}

\author{
${ }^{1}$ Hariyanto, ${ }^{2}$ Andysah Putera Utama Siahaan \\ Faculty of Science and Technology, Universitas Pembangunan Panca Budi, Medan, Indonesia \\ Email: ${ }^{1}$ hariyanto@pancabudi.ac.id, ${ }^{2}$ andiesiahaan@gmail.com
}

\begin{abstract}
The development of the era improves electronic technology to support human needs for transportation. Many vehicles created have the latest and most sophisticated features. The growth of vehicle production is increasing. One of them is a motorized vehicle. It also affects criminal acts that will increase, such as cases of vehicle theft. Motor vehicle theft cases often occur. It is because there is still a lack of security systems contained in the vehicle. Even though the vehicle is equipped with an anti-theft system, this does not affect theft. Generally, motorized vehicles currently only use dual and electric keys. The importance of a tracking device to see the location of the car will be very influential to monitor the existence of the vehicle. Tools such as GPS Tracker are one that can be used to reduce the theft of a vehicle. This review will discuss GT06N during installation in a vehicle. This GPS can help vehicle owners always be aware of the existence of vehicles anywhere, whether from SMS or the Internet. GT06N already supports real-time location with excellent accuracy.
\end{abstract}

Key Words: GPS Tracker, GT06N, location, real-time, anti-theft.

\section{INTRODUCTION:}

The technology that is developing at this time is very rapid, especially in the field of transportation and security [1]-[4]. Technology not only involves hardware, but the hardware has been combined with software that can be controlled by the user according to the desired performance. Regarding hardware, many electronic devices are developing, such as car tape, car alarm, sound system [5]. The tool is getting more and more innovative and innovative starting from how it works, its shape, to the media used. However, the more interesting the contents of the vehicle will increase the level of theft. Users are worried about the safety of their vehicles [6]. There have been many vehicle thefts that occur due to lack of anticipation and neglect of the users themselves. For example, the carelessness of a vehicle owner who left his vehicle without turning it off.

The use of vehicle security support devices has been widely circulated in the market. Because of the increasingly advanced technological developments, the tools that are present in the market are increasingly sophisticated. One that is now being hunted down is the GPS Tracker. This tool serves to detect the presence of a car that can be seen through a smartphone or the web. GPS tracker is a tool or system that determines the location of a device that is connected to a satellite by utilizing a signal [7]. The signal will send the location of the longitude and latitude where the vehicle is located. GPS Tracker determines the location in real time [8]. Tools that are now widely used by vehicle rental companies, family and personal. Stolen cars can be located for a moment too [9]. However, if the thief is more familiar with GPS, this vehicle can immediately turn off the GPS. Many features offered by this tool. A GPS Tracker that has a command feature to turn off the engine can be done by directly sending an SMS to the GPS. The GPS Tracker device placed on the car must be hidden and difficult to reach so that the device is not easily dismantled and turned off. The taking of GPS power is not recommended not to jumper the cable from the car's fuse, because if the fuse breaks the GPS Tracker dies or does not update the location. However, on average the seller of this tool will install it on the consumer's car. It is related to security guarantees and the difficulty of installation. GT06N has been widely marketed since the 2000s. It is in line with the development of internet technology which is easier to monitor vehicles that can be done with the help of cell phone providers [10]. With the GT06N review, it is expected that this tool can help users or vehicle owners feel safe.

\section{THEORIES:}

Global Positioning System (GPS) is a navigation system that uses satellites that are designed to provide instant positioning, speed and time information in almost any place on the face of the earth, at any time and in any weather conditions. While the device for receiving satellite signals that can be used by users is generally called a GPS Tracker or GPS Tracking, by using this tool it is possible for users to track the position of vehicles, fleets or cars in Real-Time. The most important part of GPS navigation systems is that some satellites are in the Earth's orbit or what we often call in space. GPS satellites currently number 24 units, all of which can transmit signals to the earth which can then be captured by the signal receiver or GPS Tracker. There are three important parts in the GPS system are [11]:

- Control Segment

- Space Segment 
- User Segment.

The GPS segment control consists of five stations located on the bases of Falcon Air Force, Colorado Springs, Ascension Island, Hawaii, Diego Garcia and Kwajalein. These five stations are eyes and ears for GPS. The control section receives the signals from the satellite, then corrected, and sent back to the satellite. The exact location correction data from this satellite is called ephemeris data, which is then sent to the navigation tool. Space Segment consists of a satellite network consisting of several satellites in the nearest circular orbit with a nominal height of about 20,183 km above the earth's surface. The signal emitted by all of these satellites can penetrate clouds, plastic, and glass, but cannot penetrate solid objects such as walls and tight trees. There are two types of waves that are currently used as satellitebased navigation tools. Each is a wave L1 and L2, where L1 runs at a frequency of $1575.42 \mathrm{MHz}$ which can be used by the general public, and L2 runs at a frequency of $1227.6 \mathrm{Mhz}$ where this type is only for military needs. User segment consists of an antenna and receiver processor that provides positioning, speed, and timeliness to the user. This section receives data from satellites via radio signals sent after being corrected by a GPS Control Segment. GPS was created to get a million benefits. Many benefits can be obtained from GPS navigation systems for people all over the world. Some of the functions and uses of the GPS are:

- GPS for Navigation

- GPS for Geographic Information Systems

- GPS for Vehicle Tracking Systems

- GPS for earthquake monitoring

\section{RESULT AND DISCUSSION:}

GT06N is the world's most popular GPS tracking device. After years of popularity around the world, it has obtained the trust, stability, and durability. Has many features, the battery-powered GT06N gives the real-time location viewing from the comfort of the electronic devices such as a computer or smartphone. It makes a suitable option for the vehicle tracking device. The following figure is the GT06N device [10].

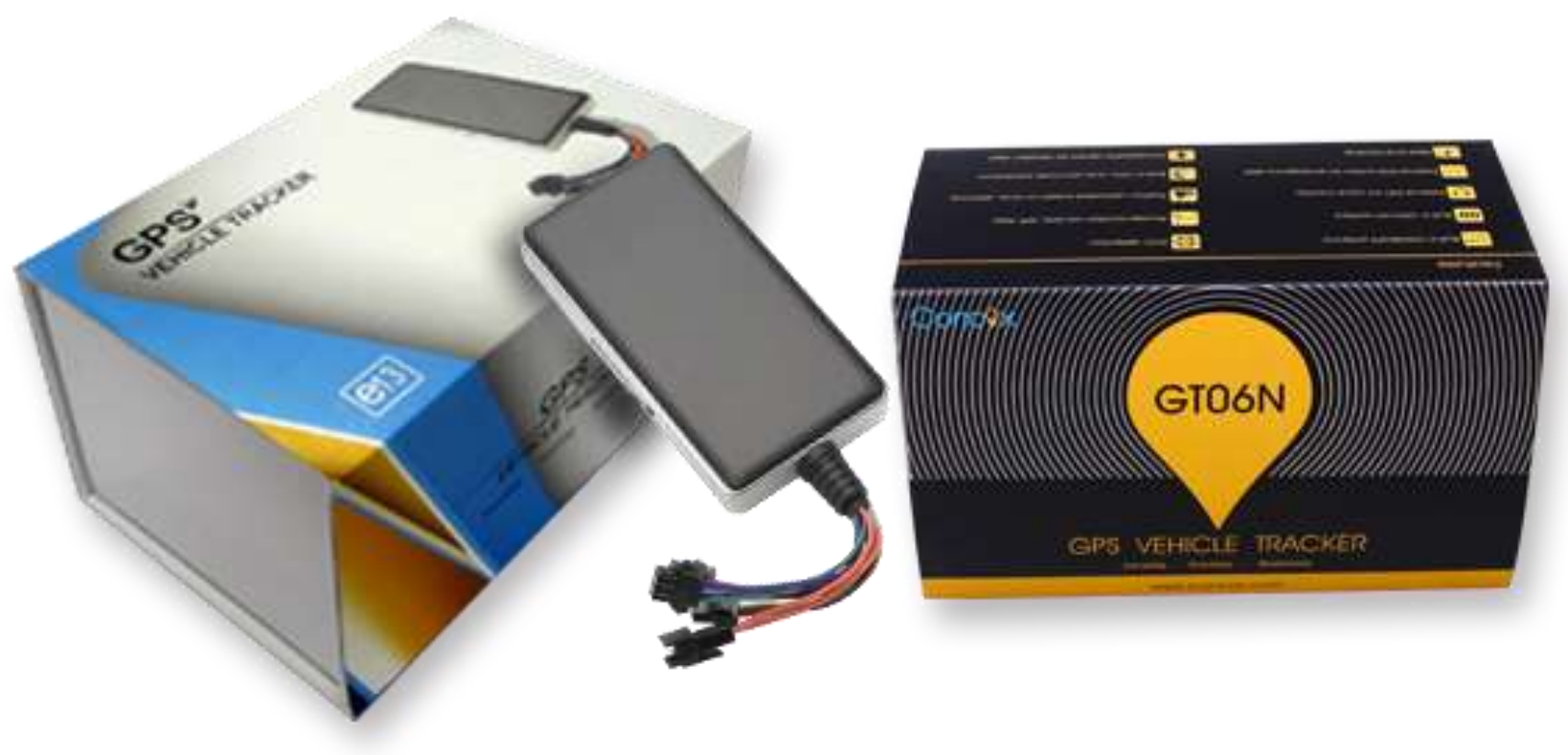

Figure 1. GT06N GPS Tracker

Economical vehicle tracking devices can be paired with various types of vehicles such as motorcycles, cars, trucks, buses, and heavy equipment. GT06N has the excellent price, quality, stability, and durability. The features contained in this tracking device product are also quite sufficient to meet the needs of vehicle supervision. The choice of GPS must be prudent because this tool will be used for an extended period. GT06N has many uses. Aside from being a safety device, this GPS tracker can be used to track the whereabouts of the vehicle and provide a real-time location of the vehicle. The location of the coordinates will be sent via SMS or the internet by using a website that has worked together on this GPS product [12]. The following figure is the GT06N wiring diagram [13]. 


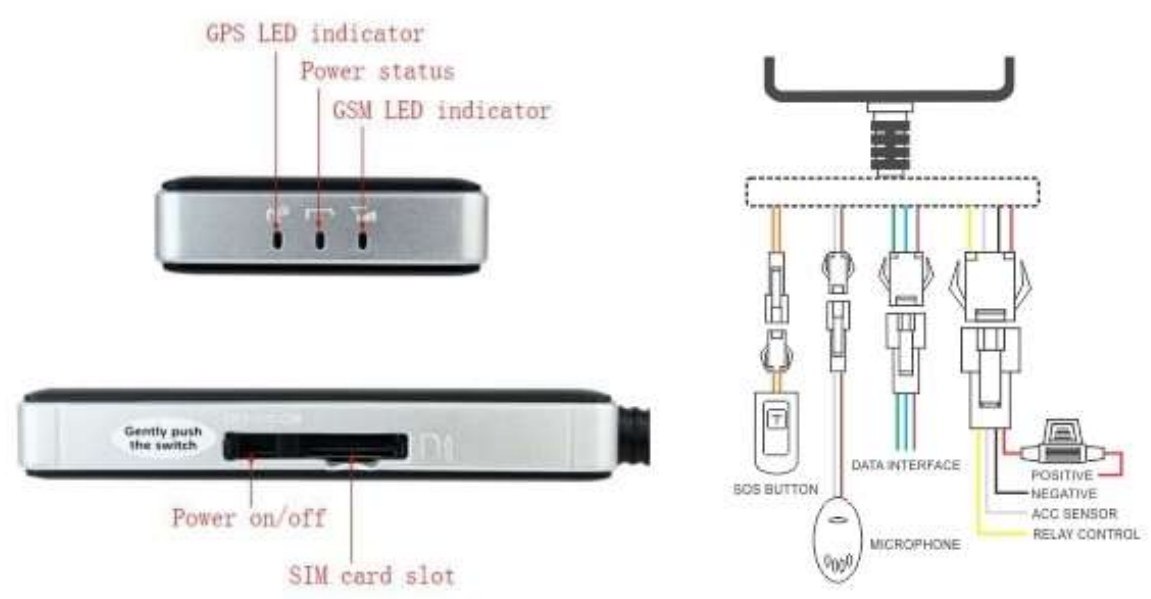

Figure 2. GT06N wiring diagram

Figure 2 describes the wiring diagram and LED indicators in GT06N. This device has three LED indicators that indicate, GPS, Power and GSM signals. On the other side, there is a SIM card slot and power button. Four cables are coming out of the device such as the SOS button, Microphone, Data Interface, and power cable. SOS button is used when an emergency occurs when the vehicle is running, and the driver can press this button to call the registered telephone number. The microphone can hear conversations in the car cabin to anticipate crime. The data interface connects GPS to a computer device. The power button is used to connect the GPS to a power source. The following table is a complete specification of the GT06N GPS device [13].

Table 1. GT06N specification

\begin{tabular}{|l|l|}
\hline \multicolumn{2}{|c|}{ Device Specification } \\
\hline Packaging Weight & $409 \mathrm{gr}$ \\
\hline $\begin{array}{l}\text { Packaging } \\
\text { Dimensions }\end{array}$ & $155(\mathrm{P}) \times$ 95(L) $\times$ 78(T)mm \\
\hline Device Weight & $96 \mathrm{gr}$ \\
\hline Device Dimensions & $105.8(\mathrm{P}) \times 54.5(\mathrm{~L}) \times 16.4(\mathrm{~T}) \mathrm{mm}$ \\
\hline Voltage & $9-36 \mathrm{VDC} / 30 \mathrm{~mA}$ \\
\hline Battery & $450 \mathrm{mAh} / 3.7 \mathrm{~V}$ Li-Polymer \\
\hline Temperature & $-20^{\circ} \mathrm{C} \sim 70^{\circ} \mathrm{C}$ \\
\hline Microphone distance & $\leq 5 \mathrm{Meter}$ \\
\hline \multicolumn{2}{|c|}{ GPS Specification } \\
\hline Chipset & MTK High Sensitivity \\
\hline Frequency & L1, 1575.42MHz C / A Code \\
\hline Channel & 66 \\
\hline Accuracy & Below 10 Meters \\
\hline Tracking & $-165 \mathrm{dBm}$ \\
\hline Acquisition & $-148 \mathrm{dBm}$ \\
\hline \multicolumn{2}{|c|}{ GSM Specification } \\
\hline Frequency & $850 / 900 / 1800 / 1900 \mathrm{MHz}$ \\
\hline GPRS type & Class 12, TCP / IP \\
\hline Memory & $64 \mathrm{MB}$ \\
\hline Phrase error & RMSPE 5, PPE 20 \\
\hline Maximum Output & $850 / 900: 33 \pm 3 \mathrm{dBm}, 1800 / 1900: 30 \pm 3 \mathrm{Bm}$ \\
\hline Frequency Error & $\pm 0.1 \mathrm{ppm}$ \\
\hline
\end{tabular}

The following table describes the procedure for sending SMS to numbers that are on a GPS device. Many commands can be sent with different functions. There is an order that serves to monitor the presence of a vehicle, and 
some can turn off the vehicle's engine during an emergency. Electronic devices sometimes experience interference due to unstable electric current or imperfect message processing. There is a reset device to factory default feature if one day the GPS has a malfunction.

Table 2. GT06N SMS commands

\begin{tabular}{|c|c|c|}
\hline No & Settings & Commands \\
\hline 1 & APN Setting & APN,APN name\# \\
\hline \multirow{2}{*}{2} & \multirow{2}{*}{ Server Setting } & SERVER,1,server-gps.com,6010,0\# (With URL) \\
\hline & & SERVER,0,172.104.52.239,0\# (With IP) \\
\hline \multirow{2}{*}{3} & \multirow{2}{*}{$\begin{array}{l}\text { GPRS Time Interval } \\
\text { Setting }\end{array}$} & TIMER,interval time\# \\
\hline & & Interval time range: $10-18000$ s. Default as $10 \mathrm{~s}$. \\
\hline 4 & Add SOS Number & SOS,A,No.1,No.2,No.3\# \\
\hline \multirow{3}{*}{5} & \multirow{3}{*}{ Delete SOS Number } & 1 SOS,D, Serial No.1, Serial No.2, Serial No.3\# \\
\hline & & 2 SOS,D,Serial No.1\# \\
\hline & & 3 SOS,D,phone number\# \\
\hline \multirow{2}{*}{6} & \multirow{2}{*}{ Center Number Setting } & CENTER,A,phone number\# \\
\hline & & Only center number can Cut-Off Petro \\
\hline 7 & Delete Center Number & CENTER,D\# \\
\hline 8 & Oil Cut-Off & RELAY,1\# \\
\hline 9 & Restore Oil & RELAY,0\# \\
\hline \multirow[t]{4}{*}{10} & Geo-fence & FENCE,ON,0,Latitude,longitude,radius,in/out\# \\
\hline & & FENCE,ON,0,0,0,radius,in/out\# \\
\hline & & If GPS is located, this sms means the latitude and \\
\hline & & longitude is present location \\
\hline 11 & Disable Geo-fence & FENCE,OFF\# \\
\hline 12 & Reboot Device & RESET\# \\
\hline \multirow{3}{*}{13} & \multirow{3}{*}{ Time Zone Setting } & GMT,E/W,hours,minutes\# \\
\hline & & [Time zone(hours) range:0 \pm 12 ; Time \\
\hline & & zone(minutes) range:15/30/45] \\
\hline \multirow{3}{*}{14} & \multirow{3}{*}{ GPRS Status Setting } & Activate GPRS: GPRSON,1\# \\
\hline & & Disactivate GPRS: GPRSON,0\# \\
\hline & & Default as GPRS ON. \\
\hline \multirow{2}{*}{15} & \multirow{2}{*}{ Voice-Monitor Delay } & DELAY,time\# \\
\hline & & Time range: $5 \mathrm{~s}-18 \mathrm{~s}$. Default as $10 \mathrm{~s}$. \\
\hline 16 & Factory Setting & FACTORY\# \\
\hline 17 & Modify User Password & - \\
\hline \multirow{2}{*}{18} & \multirow{2}{*}{$\begin{array}{l}\text { Alarm GPS Working } \\
\text { Time }\end{array}$} & TIMESET,time\# \\
\hline & & Time range: $1-999$ mins. Default as $20 \mathrm{mins}$ \\
\hline \multirow{2}{*}{19} & \multirow{2}{*}{$\begin{array}{l}\text { Sensor Alarm Time } \\
\text { Setting }\end{array}$} & DEFENSE,time\# \\
\hline & & Time range: $1-60 \mathrm{mins}$. Default as $10 \mathrm{mins}$ \\
\hline \multirow{3}{*}{20} & \multirow{3}{*}{ Sensor Detecting Time } & SENSOR,detect time,alarm time\# \\
\hline & & Detect time range:0-300sAlarm time range: $10-300 \mathrm{~s}$ \\
\hline & & SENSOR,0\# to disable vibration alarm function. \\
\hline \multicolumn{3}{|r|}{ CHECKING } \\
\hline 21 & $\begin{array}{l}\text { Checking Software } \\
\text { Version }\end{array}$ & VERSION\# \\
\hline 22 & Checking Parameters & PARAM\# \\
\hline
\end{tabular}




\begin{tabular}{|c|l|l|}
\hline 23 & $\begin{array}{l}\text { Checking Simplify } \\
\text { parameters }\end{array}$ & SCXSZ\# \\
\hline 24 & $\begin{array}{l}\text { Checking GPRS } \\
\text { Parameter }\end{array}$ & GPRSSET\# \\
\hline 25 & Location checking & \multirow{2}{*}{ WHERE\# } \\
\cline { 2 - 3 } & (Get Coordinate) & STATUS\# \\
\hline 26 & Status & \multirow{2}{*}{ URL\# } \\
\hline 27 & Location checking & SEEFENCE\# \\
\cline { 2 - 3 } & (Get Google Map link) & \\
\hline 28 & Geo-fence status & (2) \\
\hline
\end{tabular}

Besides having an SMS feature, GPS devices can send coordinates through internet data. However, cards registered with GPS must have an internet data plan so that GPRS works appropriately. Several tracking providers offer vehicle monitoring services such as OrangeGPS, DuniaTrace, IDTrack and many more. The following picture is a display from the GPS monitoring website.

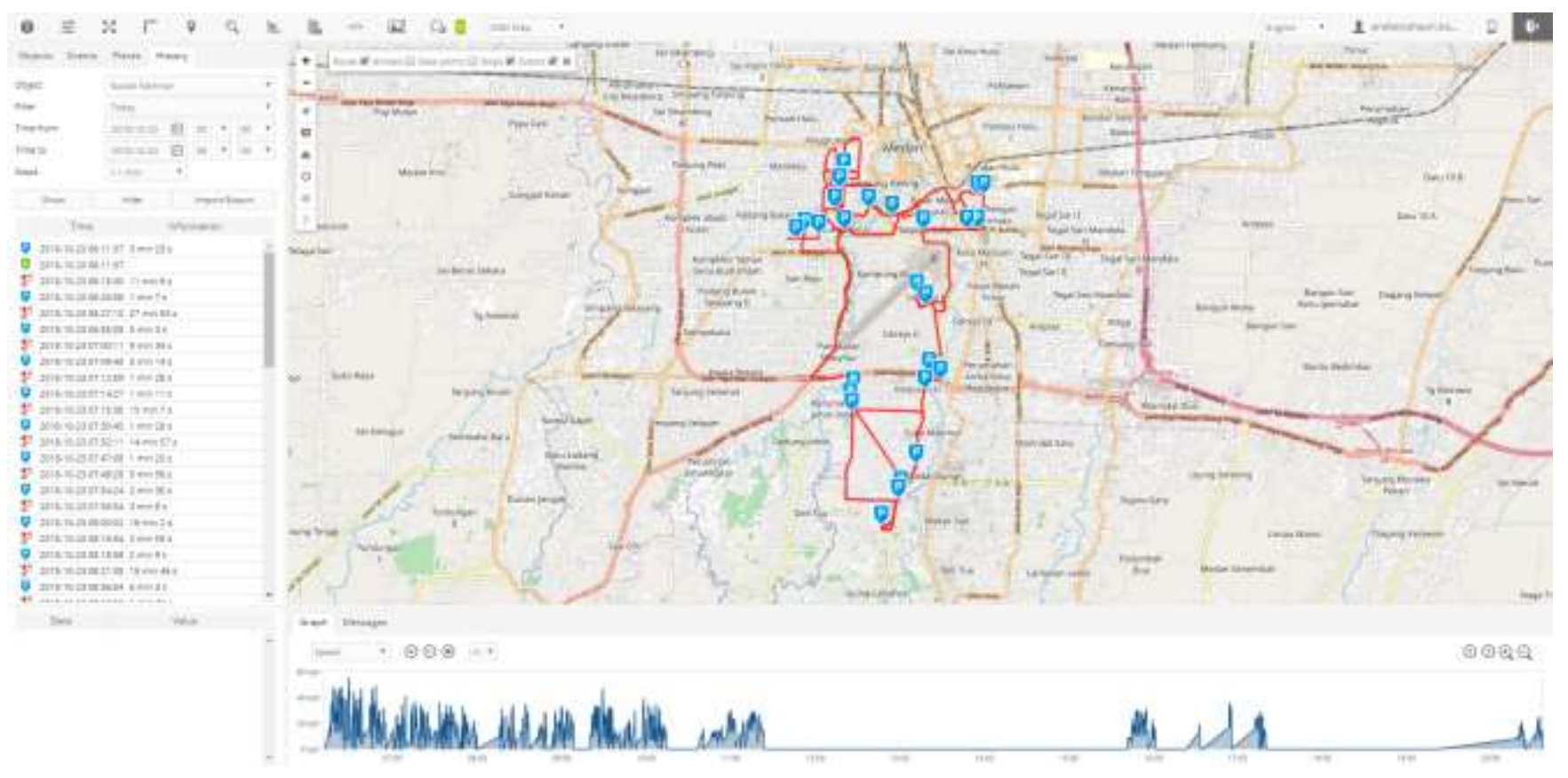

Figure 3. Dunia Trace GPS tracking monitoring website

Figure 3 describes the website "Dunia Trace." This website is located at http://duniatrace.com/tracking.php. The image that appears on the website is the history of the vehicle journey and the time of the stopover. In this data, it will be displayed in full how long the vehicle runs, the vehicle stops and travel speed on each trip. The database is extensive enough so that it can accommodate several weeks of travel history. So that if there is something that becomes a problem in the previous days, can be found again with the history feature.

\section{CONCLUSION:}

Security is needed at this time. Vehicles are items that are very valuable to be guarded. GPS tracker is a tool needed to determine the location of a vehicle. This tool can record the number of trips and stops made by the driver. Not only that, but this tool can also turn off the vehicle remotely using SMS. This tool works using SIM cards and internet data packages. The weakness of this tool if the perpetrator of a crime performs jamming on the GSM signal, this tool will not function. The GPS tracker cannot send a location or danger warning to the telephone number that has been registered.

\section{REFERENCES:}

1. M. Iqbal, M. A. S. Pane, and A. P. U. Siahaan, "SMS Encryption Using One-Time Pad Cipher," IOSR J. Comput. Eng., vol. 18, no. 6, pp. 54-58, 2016.

2. R. D. Sari, Supiyandi, A. P. U. Siahaan, M. Muttaqin, and R. B. Ginting, "A Review of IP and MAC Address 
Filtering in Wireless Network Security," Int. J. Sci. Res. Sci. Technol., vol. 3, no. 6, pp. 470-473, 2017.

3. S. Ramadhani, Y. M. Saragih, R. Rahim, and A. P. U. Siahaan, "Post-Genesis Digital Forensics Investigation," Int. J. Sci. Res. Sci. Technol., vol. 3, no. 6, pp. 164-166, 2017.

4. S. Haryati, A. Ikhwan, D. Arisandi, Fadlina, and A. P. U. Siahaan, "Quality Assurance in Knowledge Data Warehouse," Int. J. Sci. Res. Sci. Technol., vol. 3, no. 6, p. 239-242], 2017.

5. M. Zhu et al., "Public Vehicles for Future Urban Transportation," IEEE Trans. Intell. Transp. Syst., vol. 17, no. 12, pp. 3344-3353, Dec. 2016.

6. F. B. B. Alzahri and M. Sabudin, "Vehicle Tracking Device," in 2016 International Conference On Advanced Informatics: Concepts, Theory And Application (ICAICTA), 2016, pp. 1-6.

7. G. Williams, P. King, and K. Doughty, "Practical issues in the selection and use of GPS tracking and location technologies to support vulnerable people at risk of becoming lost or threatened," J. Assist. Technol., vol. 5, no. 3, pp. 146-151, Sep. 2011.

8. N. Haliti, A. Kadriu, and M. Jusufi, "An approach for speed limit determination for vehicle tracking in case of GID ambiguity and lack of information in navigation maps," Int. J. Pervasive Comput. Commun., vol. 13, no. 3, pp. 252-263, Sep. 2017.

9. D. P. Dirgantoro, "GPS Tracker, Menambah Keamanan Dan Bisa Untuk Mengintai," OTODriver, 2016. [Online]. Available: http://otodriver.com/article/view/gps-tracker-menambah-keamanan-dan-bisa-untukmengintai/yc1tWyX2uWDimek2YIMRTAs3LeqaklDcB22bge1jvJg. [Accessed: 10-Oct-2018].

10. Concox, "Vehicle Tracker," 2018. [Online]. Available: http://www.iconcox.com/support/download.html.

11. Mandalamaya, "Pengertian GPS Cara Kerja GPS Dan Fungsi GPS," 2015. [Online]. Available: $\mathrm{http}: / / w w w . m a n d a l a m a y a . c o m / p e n g e r t i a n-g p s-c a r a-k e r j a-g p s-d a n-f u n g s i-g p s /$. [Accessed: 12-Oct-2018].

12. IDTRACK, "Cara Membedakan GPS Tracker GT06N Asli atau Palsu," 2017. [Online]. Available: https://idtrack.co.id/cara-membedakan-gps-tracker-gt06n-asli-atau-palsu/. [Accessed: 12-Oct-2018].

13. SmartGPS, "PANDUAN PENGGUNAAN GPS TRACKER GT06N," 2018. [Online]. Available: http://www.smartgps.co.id/tracker-gt06n.html. [Accessed: 10-Oct-2018]. 